\title{
BTK inhibitor TG-1701
}

National Cancer Institute

\section{Source}

National Cancer Institute. BTK inhibitor T G-1701. NCI Thesaurus. Code C162479.

An orally available irreversible inhibitor of Bruton's tyrosine kinase (BTK; Bruton ag ammag lobulinemia tyrosine kinase) with potential antineoplastic activity. Upon administration, BTK inhibitor TG-1701 covalently binds to and irreversibly inhibits BTK activity, thereby preventing the activation of the B-cell antigen receptor (BCR) signaling pathway and BT K-mediated activation of downstream survival pathways. This may inhibit the growth of malignant B-cells that overexpress BTK. BTK, a member of the Src-related BTK/Tec family of cytoplasmic tyrosine kinases, is overexpressed or mutated in B-cell malignancies; it plays an important role in the development, activation, signaling, proliferation and survival of B-lymphocytes. 